\title{
Environmental History
}

Volume 6

Series editor

Mauro Agnoletti, Florence, Italy 
More information about this series at http://www.springer.com/series/10168 
Estelita Vaz • Cristina Joanaz de Melo Lígia M. Costa Pinto

Editors

\section{Environmental History in the Making}

Volume I: Explaining

囪 Springer 


\section{Editors}

Estelita Vaz

Escola de Ciências

Universidade do Minho

Braga, Portugal

\section{Lígia M. Costa Pinto}

NIMA, Escola de Economia e Gestão

Universidade do Minho

Braga, Portugal
Cristina Joanaz de Melo

IHC, Universidade Nova de Lisboa

Lisboa, Portugal
ISSN 2211-9019

Environmental History

ISBN 978-3-319-41083-8

DOI 10.1007/978-3-319-41085-2
ISSN 2211-9027 (electronic)

ISBN 978-3-319-41085-2 (eBook)

Library of Congress Control Number: 2016954320

(C) Springer International Publishing Switzerland 2017

This work is subject to copyright. All rights are reserved by the Publisher, whether the whole or part of the material is concerned, specifically the rights of translation, reprinting, reuse of illustrations, recitation, broadcasting, reproduction on microfilms or in any other physical way, and transmission or information storage and retrieval, electronic adaptation, computer software, or by similar or dissimilar methodology now known or hereafter developed.

The use of general descriptive names, registered names, trademarks, service marks, etc. in this publication does not imply, even in the absence of a specific statement, that such names are exempt from the relevant protective laws and regulations and therefore free for general use.

The publisher, the authors and the editors are safe to assume that the advice and information in this book are believed to be true and accurate at the date of publication. Neither the publisher nor the authors or the editors give a warranty, express or implied, with respect to the material contained herein or for any errors or omissions that may have been made.

Printed on acid-free paper

This Springer imprint is published by Springer Nature

The registered company is Springer International Publishing AG Switzerland 


\section{Contents}

Part I Approaches - Social Bondage to Mathematics, Arts or Socio-Biology

1 Cognition and Natural Disasters: Stimulating an Environmental Historical Debate.......................................................................

Niki Pfeifer

2 Peopling Landscapes Through Art

Mandy Martin

3 The Power of Stories in the South Moresby Controversy:

A Narrative Network Analysis

Alexandra Vlachos

4 Exploring Environmental Literacy from a Historical

Perspective: How Observations of the Arctic Natural Environment by a Nineteenth-Century Scholar Resulted in a Proposal for Establishing National Parks in the Nordic Countries

Seija A. Niemi

Part II Proposing - Concepts, Sources, Methodologies

5 Eco-fusion of Alien and Native as a New Conceptual Framework for Historical Ecology

Ian D. Rotherham

6 Sustainable Development in Brundtland and Beyond:

How (Not) to Reconcile Material Wealth, Environmental

Limits and Just Distribution

Iris Borowy 
7 Hidden Treasures: Challenging Traps of Historical Sources for Environmental History

Klára Woitschová

8 Vegetation Analysis as a Source of Historic Information The Case of Madeira Island

Sandra Kiesow and Klaus Dierssen

Part III Clarifying Results - Interchange of Psico-Social with Natural and Analytical

9 Fire on the Hills: An Environmental History of Fires and Fire Policy in Mediterranean-Type Ecosystems Mário Gonzalez Pereira, Jack P. Hayes, Char Miller, and Daniel E. Orenstein

10 Beyond Colonialism: Towards a New Environmental History of India

Arivalagan Murugeshapandian

11 Where Many Rivers Meet: River Morphology and Transformation of Pre-modern River Economy in Mid-Ganga Basin, India Vipul Singh

12 Notes from the Edges. Environmental History Writing in a Mediterranean "Periphery" 207 Vaso Seirinidou

Part IV Blurring All: New Interpretations, Old Themes, Different Outcomes

13 Science, Society, and Knowledge of the Columbian Exchange: The Case of Cannabis

Chris S. Duvall

14 History of the Colonization of Minas Gerais: An Environmental Approach Alexia Helena de Araujo Shellard

15 Locusts in Southern Settler Societies: Argentine and Australian Experience and Responses, 1880-1940 259

Edward Deveson and Alejandro Martinez 
Part V Resetting Data - Information Upon

Classic Subjects (Crossing Methodologies and Proposing

New Interpretations)

16 Locust Invasions, Climatic Factors and Human Affairs in Modern Age Mediterranean

Elina Gugliuzzo and Giuseppe Restifo

17 Wood for Burning: The Continuity of Woodland

Management in Medieval and Early Modern France

Richard Keyser

18 Firewood and Charcoal Consumption in Madrid during Eighteenth Century and Its Effects on Forest Landscapes

Javier Hernando Ortego and Gonzalo Madrazo García de Lomana

19 Bambi in Sherwood Forest and the Great Deer

Escape c. 1703-1711

Sara E. Morrison 


\section{Introduction}

Environmental History in the Making contains selected contributions from the 2nd World Conference on Environmental History, held in Guimarães, Portugal, 8-12 July 2014.

It is quite clear that environmental history has been established as a discipline. However, the works presented went far beyond that driver of discussion. Researchers from the five continents presented new problems and further information, and they also formulated new hypotheses and discussed the corresponding results.

A sample of scientific responses within their historical contexts that explain past and present uses of the planet is presented in this book, together with possible proposals or solutions for forthcoming action.

Looking at the complete set of articles, it emerges quite clearly that historical data can be a fundamental tool to plan forthcoming environmental interventions.

As a matter of fact, the underlying theme of this manuscript is about knowing the past, understanding the present and planning the future. In other words, Environmental History in the Making gives, in practice, environmental historical information about the past and suggests a conceivable better future.

These views are in line with the prevalent interpretation of the environment. Despite cultural, economic, political or religious differences, an evolving planetary solution is needed to reverse ecological loss. This new paradigm tempers political and cultural divisions with total respect for cultural diversity. It emerges as the ground for a worldwide future, while religion, capitalism or socialism ceases to be recognised as a possible universal socio-economic-cultural paradigm.

This new paradigm goes far beyond models of resolutions built in the aftermath of the Second World War. Those were conceived under the legitimation of the UN institutions that was framed by the colonial background and thereafter by the Cold War. The environmental paradigm is a quest for the common good, defending human rights and access to basics such as nutrition or medical care. It argues for sharing resources instead of basic monopolistic control on water or power sources.

The articles integrating this book substantiate this new paradigm. The organisation in parts, "Explaining" and "Acting", intends to stress the resourcefulness of environmental history and its vision towards the future. 
Thus, in Part I of the book, "Explaining", the main focus of organisation is about how to think in order to do and how to test cross-data analyses to propose and present new data and stories:

1. Approaches - Social bondage to mathematics, arts or socio-biology

2. Proposing - Concepts, sources and methodologies

3. Clarifying results - Interchange of psico-social with natural and analytical

4. Resetting data - Information upon classic subjects crossing methodologies and producing new interpretations

5. Blurring all - New interpretations, old themes and different outcomes. How multi- and interdisciplinarity allow a confrontation of data proposing quite different interpretations on the same object

In Part II, the main driver of the organisation is about "acting", offering new insights on new outcomes of classic themes or new interpretations of past uses of resources or changed landscapes. It is also our intention to stress how the awareness of the past helps to promote civic and political agency in the present.

Part II comprises:

6. Using resources - Narratives of resource exploitation in time and its evolution in the long run

7. Transforming in situ - Manipulating, changing and evolving landscapes, waterscapes and airscapes (classical approach of territorial changes, causes, actors and consequences)

8. Transferring (migrations) - Resource exploitation and trade, local to global (native sources, new case studies and transcontinental approaches!)

9. Spreading (aliens, exotics) - Reinterpreting evil to evolving with both positive and negative impacts

10. Conscience of loss and improving - Present awareness of how we have arrived where we are, undoing inappropriate territorial policies with environmental impact

11. Civic and political agency - History as memory of social process, knowing the past and planning the future

A few main ideas emerge when one reads the entire spread of contributions published here.

This book moves ahead from a framework looking for guilt and for whom to blame in the past for ecological loss to a framework of understanding the processes leading to current environmental circumstances and characteristics. This is achieved by analysing the mutual shaping of natural and social factors.

In the long run, natural and human action together gave rise to a wide range of resource uses, displacement, transfer and distribution. The transformations were implemented either intentionally or randomly. The corresponding multiplicity of shaped ecosystems, occupied by a wide diversity of animal, botanic and human populations generating different cultures, offers a transcultural and transdisciplinary set of approaches. 
Researching past actions and consequences helps us to understand the present behaviour of nature and the emergence of new landscapes. Understanding past interactions between the human and natural spheres and its results at the local and global levels, it is possible to gain a better understanding and predictive power of how nature behaves. Consequently, hazards may be prevented (or its impacts minimised) and ecosystems managed in order to care for the common good without harming cultural, psychological or anthropological heritage and identity.

Following the universal status that "the environment" has acquired as a solution for life as we know it on the planet, some of the papers presented here clearly launch the knowledge of the past as an operative tool to project actions in our own time. They point to actions that might reverse economic, political, social and cultural environmentally unfriendly drivers. The understanding of the negative results of past interactions between humans and nature might allow the shaping of positive results in the future.

Yet, there is no spark of any intention to disguise the consolidated processes that contributed to damaging many areas of the planet. The research here confirms and unveils stories of ecologically harmful political actions towards mastering the exploitation of natural resources. These policies, in many instances, were accompanied by the monopoly of social control over the populations of, for instance, India, Rhodesia (Zimbabwe), Uganda or Bolivia and Brazil.

There is an ongoing debate to explain why prior analysis, which does not combine historical analysis with all the other sources of data, may lead to misperceptions and the diffusion of history that is actually wrong. Such is the case of the papers analysing themes from pollen distribution to iconography. In addition, there is a wide presence of papers that provide the historical context to explain why conclusions drawn from outside conjunctures and cultural frameworks may lead to a misunderstood history and incorrect interpretations, including how this tension can be resolved.

The insights of psychology, sociology, anthropology and the arts by way of performances and tradition propose new avenues for interpreting bondages to landscape and rooted cultural behaviours, which in turn explain resistance or acceptance of human changes to landscapes.

These approaches might constitute the DNA of human historical processes which in turn translate into a useful grid to read how humans have interacted with the environment and provide a basis to formulate future policies to regulate the relationship between humans and the environment.

Before interfering with deep-rooted cultural heritage, problems of historical origin can explain present conflicts between the biosphere and the human sphere. In addition, a historical context can provide a grid to read the degree of acceptance of territorial change. These changes can be rooted in traditions and can relate to the extraction, use, diffusion and trade of natural resources in different cultures. Finally, the historical context is key to understanding how delicate environmental management can be in different parts of the world, particularly when it comes to unhealed historical wounds. 
New insights are then brought to light in environmental history by the stepping in of environmental humanities, social sciences, arts, anthropology and sociology, together with the contributions of natural sciences.

Indeed, this book presents mature analyses combining current problems and historical contexts to address environmental issues when inquiring into the past. There is a very clear attitude of not trying to find "ecological blame" or "indisputable ecological criminals" at any cost. In various stages, both present concerns and then perspectives, actors and limitations of knowledge within given spatial and time coordinates and so avoid misguided interpretations.

Albeit coming across with horizons of hope as much as of fear about the future, the analyses focus on positive and negative impacts resulting from past undertakings, performing studies both on the bad and good environmental management of former periods. Studies that progressively got thicker in this direction balance perspectives by paying attention not only to the crucial space-time contexts but also crossing methodologies and sources of many origins.

The texts stress the pressing need to access local data, translated to more diffused languages in the publishing sphere. Indeed, one of the most important contributions for a wider understanding of transfers of species and natural resources around the world, in the long run, intentionally or unexpectedly, is local information on the historical ground.

Indeed its diffusion and conclusion can change the course of given discussions in international forums, for example, concerning the stories and versions of resource transfers from Russia and China to Portugal, diverting from Dutch, English or French syntheses produced so far, as analysed in some of the papers in this volume.

Examples of new interpretations and reinterpretations of classic theories can be observed in this book concerning, for example, the introduction of botanic and animal species from India and Africa in Brazil; sugar plantations in Formosa Island (Taiwan) by the Chinese in the fourteenth century before the arrival of the Dutch in the sixteenth century; pets transferred as sacred or exotic like apes from India to Europe and America; the mining extraction in Brazil much earlier than the Portuguese "discovery" of Minas Gerais; the mining and trade of metallic resources between Japan and Korea; the fisheries on whales in the Northern Sea by the Russians and the Portuguese as steady but not depleting industries could be drawn, with processes so far unknown and now disclosed; or the importance of arts in stating and producing historical records or using representation to explore meanings of the same subjects and objects in different cultures.

The information unveiled in native languages also provides a new insight on the role of public health calamities and the diffusion of parasites in wet environments, as well as the launching of urban planning, for instance, in Russia.

The story of the abomination of resource depletion analysed as an ongoing horror since "ever" in opinion-making produced in the twentieth and twenty-first centuries becomes quite different when putting the same action in former periods attending to demography and scale of collection. In addition, the records on health 
and medicine linked to parasite diffusion suggest causes for social displacement and urban projection as what happened in Russia.

Historical analysis is also bringing to light reinterpretation of species transfers and migrations and deals with the positive as well as negative consequences of this process. Insufficient mono-disciplinary historical data was considered to result in misleading conclusions concerning this topic. In this book, a paper on cannabis circulation in the world takes this perspective.

Moreover the analysis of botanic or fauna distribution across spaces (solid and water, air) and time also provides information on climate behaviour and natural or manmade shaping of new landscapes through time. This is clear, for example, in the nineteenth-century scientific narrative about Argentina and Australia.

Decisions based on one side of science applied universally to different parts of the world, during colonial administrations for instance, were not only ecologically harmful in regions of India, the Middle East and North Africa, but, at the same, the decision making which disregarded cultural heritage led to huge conflicts in India, the low parts of Eastern Europe surrounding the Black Sea, Maghreb, Central Africa and Latin America, as well as in the USA and Canada.

Regardless of the disciplinary field from where the research starts off, interdisciplinarity, multidisciplinarity and transdisciplinarity are applied no longer as an adventure of attempts, uncertainty of results or a justification of the disciplinary field to make it more scientific but are integrated by their respective methodologies. This perspective allows the crossing of perspectives and sources seeking for better knowledge of the past, of local and collective memory and of the possibilities and limitations of actors to manage territories, ecosystems, religion, politics, power, war and economics.

Multidisciplinary, interdisciplinary and transdisciplinary approaches are almost "taken for granted" while concepts themselves are not. They are carefully posed as the drivers of the approaches from eco-fusion to psychological bondage with nature proposing sustainable approaches.

As a matter of fact, attitudes towards conceptualisation have altered. There is an intention of merging existing or creating new concepts in the framework of an already existing environmental history. There seems to have been a shift from trying to explain what environmental history is to how it is being shaped. It is explained how environmental history uses, copes with and accepts concepts from other sciences, instead of "adjusting" them from other disciplines or fields of work (as in many books/conferences before) to find a rough way of making them usable in historical analyses as also a way to make the discipline (environmental history) credible.

Objects as subjects became free from a dependent mono-disciplinary heritage coming either from natural or social sciences. This programme offers a very good combination of nature and natural "heroes" as main characters of the narratives; indeed themes like aliens, invasive species, naturalisation, degradation and depletion are also put in historical context, even when destruction occurred.

There is, in the papers presented here, considerable clarification of how, when and why action and impacts occurred while looking at several perspectives. There is 
a shift from "green imperialism" to species transfer before jumping into conclusion of finding the blame on the human side. There is an almost general concern in stressing mutual interaction between natural and human factors about keeping, changing, transforming and shaping landscapes, waterscapes and "airscapes".

Such development can be quite efficient to produce new data and confirm or deny results of former resources and interpretations moving forward on knowing more and better about historical ground as to inform possibilities of environmental history as applied science for political and civic agency.

Thus Environmental History in the Making presents material for a synthesis of tendencies in the making of environmental history bringing light onto the past as a useful intellectual tool for present and future political agenda.

Escola de Ciências

Estelita Vaz

Universidade do Minho

Braga, Portugal

IHC, Universidade Nova de Lisboa

Cristina Joanaz de Melo

Lisboa, Portugal

NIMA, Escola de Economia e Gestão

Lígia M. Costa Pinto

Universidade do Minho

Braga, Portugal 